\title{
Pemilihan Model Scrum Dalam Pengembangan Sistem Monitoring Menggunakan Metode Agile Untuk Evaluasi Clinical Pathway
}

\author{
Lalu Mutawalli ${ }^{1}$, Khairul Imtihan ${ }^{2}$, Wire Bagye ${ }^{3}$ \\ STMIK Lombok ${ }^{1,2,3}$ \\ laluallistilo@gmail.com, khairulimtihan31@gmail.com, wirestmik@gmail.com
}

\begin{abstract}
Abstrak : Rumah sakit sebagai institusi pelayanan kesehatan selalu dituntut memberikan pelayanan yang berkualitas, efektif, dan akuntabel. PERSI membentuk panduan untuk menyusun standar pelayanan agar untuk mendukung pelayanan kesehatan di rumah sakit lebih akuntabel dan efisien yang disebut dengan istilah clinical pathway. Clinical pathway digunakan untuk mencatat secara sistematis setiap intervensi yang diberikan kepada pasien. Dalam implementasinya clinical pathway tidak selalu berjalan sempurna hal ini disebabkan oleh berbagai hal seperti kuranya sumberdaya (peralatan dan fasilitas kesehatan lainnya), juga diakibatkan oleh kelalaian dari pelaksana teknis seperti, dokter, perawat, tenaga gizi, dan farmasi. Sistem monitoring clinical pathway menjadi penting untuk mengetahui hambatan yang muncul. Sistem monitoring dapat mendukung proses evaluasi agar lebih cepat. Pada penelitian ini sistem dikembangkan menggunakan metode agile dengan model scrum. Penelitian dilakukan di Rumah Sakit Umum Islam Harapan Anda Kota Tegal melibatkan yang berperan langsung dalam menggunakan sistem yaitu Manajemen Perawatan Pasien (MPP). Hasil uji fungsionalitas terbagi menjadi tiga, pertama hasil kualitas sistem sebanyak $76 \%$ sesuai dengan fungsinya. Kedua penilaian terhadap kualitas informasi, nilai kualitas informasi dihasilkan sebanyak $68 \%$ sesuai dengan fungsinya. Ketiga penilaian terhadap kualitas layanan diperoleh hasil sebanyak $63 \%$ sesuai dengan fungsinya.
\end{abstract}

Kata Kunci - Sistem, Evaluasi, Monitoring, Clinical Pathway

\begin{abstract}
Hospitals as health care institutions are always required to provide quality, effective and acute services. PERSI forms a guideline for developing service standards so that it supports more accountable and efficient hospital health services called clinical pathways. Clinical pathways are used to systematically record each intervention given to patients. In its implementation, the clinical pathway does not always work perfectly, this is caused by various things such as the lack of resources (equipment and other health facilities), also caused by the negligence of technical implementers such as doctors, nurses, nutritionists, and pharmaceuticals. The clinical pathway monitoring system is important to know the obstacles that arise. The monitoring system can support the evaluation process to be faster. In this study, the system was developed using the agile method with the scrum model. The study was conducted at Harapan Harapan General Hospital in Tegal City involving those who played a direct role in using the system, Patient Care Management (MPP). The functional test results are divided into three, the first system quality results as much as $76 \%$ according to its function. Second, the assessment of the quality of information, the value of the quality of information produced as much as $68 \%$ according to its function. The three assessments of service quality obtained results as much as $63 \%$ according to its function.
\end{abstract}

Keywords - System, Evaluation, Monitoring, Clinical Pathway

\section{PENDAHULUAN}

Rumah sakit merupakan salah institusi yang memiliki domain pada jasa pelayanan kesehatan, saat ini rumah sakit selalu di tuntut memberikan mutu pelayanan lebih efisien dan akuntabel. Efisien dan akuntabel yang di maksud adalah tindakan (treatment) yang diberikan selalu terdokumentasi, tindakan yang diberikan kepada pasien selalu terencana sesuai dengan standar. Standar tindakan yang akan diberikan kepada pasien disebut dengan istilah clinical pathway. Clinical pathway dibuat untuk memberikan rincian tindakan perawatan yang harus dilaksanalan dari hari kehari (Sulistiyo et al., 2015). Clinical pathway merupakan sebuah pedoman yang digunakan untuk melakukan tindakan klinis berbasis bukti (Sutisna, 2017).

Clinical pathway juga dapat menggambarkan proses mulai saat penerimaan pasien hingga pemulangan (Rahma, 2013). Dengan adanya clinical pathway yang digunakan sebagai standar pelayanan kesehatan di rumah sakit dapat meningkatkan kualitas perawatan pasien (Vanhaet, 2007). Tahapan dilakukan untuk penyusunan clinical pathway di rumah sakit mulai dari pembentukan tim, penyusun clinical pathway, penyusunan pedoman klinis, analisis bauran kasus, menetapkan pengukuran proses dan outcome, serta dokumentasi calinical pathway (Djasri, 2016). 
Pengembangan sistem evaluasi clinical pathway dapat membantu pimpinan di rumah sakit untuk memonitoring penerapan calinical pathway di rumah sakit. Walli mengembangkan sistem membantu dalam melakukan analisis implementasi clinical pathway (Wally et al., 2013). Sjaf dan junaidi mengembangkan sistem untuk melakukan evaluasi terhadap clinical pathway (Sjaf et al., 2015). Huan mengembangkan sistem audit untuk monitoring clinical pathway (Huang et al., 2016). Sistem pendukung keputusan untuk analisa data implementasi clinical pathway (Kopec et al., 2004). Bebrapa penelitian sebelumnya telah berupaya dalam mengembangkan dan membuat sistem untuk membantu melakukan monitoring dan evaluasi clinical pathway. Akan tetapi, sifat clinical pathway disetiap rumah sakit memiliki karakteristik masing-masing.

Pada kasus penelitian ini berfokus pada kasus yang terdapat pada rumah sakit umum islam harapan anda kota tegal. Rumah sakit Umum Islam Harapan Anda merupakan salah satu rumah sakit di kota tegal, saat ini rumah sakit telah menyusun clinical pathway sebagai standar perawatan pasien. Dalam implementasinya clinical pathway tidak selalu berjalan dengan sempurna. Berbagai hal yang menyebabkan clinical pathway tidak berjalan deangan sempurna adalah peralatan yang tidak tersedia selain itu juga disebabkan oleh kelalaian dari sumber daya manusia yang melaksanakan perawatan. Sumberdaya manusia meliputi dokter, perawat, tenaga gizi, dan apoteker selanjutnya disebut dengan istilah multidisplin.

Berdasarkan informasi dari wakil direktur pelayanan keperawatan pasien (dr. Silviana) monitoring dan evaluasi clinical pathway memakan waktu yang lama. Selain itu, monitoring dan evaluasi clinical pathway tidak dapat dilakukan setiap saat. Perlu pengembangan sistem yang dapat memonitoring dan melakukan evaluasi untuk mengatasi kendala tersebut. Sistem dikembangkan menggunakan metode agile dengan model scrum. Sistem dapat memberikan penilaian terhadap tugas dan tanggung jawab setiap multidisiplin, monitoring penilaian dan kepatuhan setiap profesi terhadap clinical pathway sehingga pelayanan kesehatan yang diberikan oleh rumah sakit menjadi lebih baik.

\section{METODE PENELITIAN}

\subsection{Materi}

Penelitian dilakukan di Rumah Sakit Umum Islam Harapan Anda Kota Tegal. Data yang digunakan adalah data sekunder berupa dokumen clinical pathway. Dokumen clinical pathway yang prosedur tata laksana perawatan. Prosedur perawatan tersebut meliputi:

1. Kegiatan

Kegiatan menjelaskan alur tindakan yang harus dilakukan oleh setiap profesi seperti dokter, perawat, farmasi, dan gizi. Kegiatan berisi tatalaksana seperti, asesmen awal, uji laboratorium, uji radiologi, konsultasi, asesmen lanjutan, diagnosis, discharge planning, edukasi terintegrasi, terapi medika mentosa, tatalaksana intervensi, monitoring dan evaluasi, mobilisasi dan rehabilitasi, outcome, kriteria pulang, dan rencana pulang.

2. Uraian kegiatan

Uraian kegiatan menjelaskan secara detail tentang kegiatan dan jenis-jenis kegiatan yang dilakukan, misalnya uji laboratorium. Uji laboratorium pada penyakit demam berdarah memiliki uraian kegiatan seperti Uji $H B, H T, W B C, T R O M B O C Y T, N S 1$, MGM, IGG.

3. Hari penyakit

Hari penyakit digunakan untuk mengetahui berapa lama pasien menderita penyakit.

4. Hari rawat

Pada hari rawat menjelaskan berapa lama pasien telah di lakukan rawat inap, semenjak pasien baru masuk hingga pemulangan.

\subsection{Metode dan Model}

\section{Metode Agile}

Metode angile biasanya menggunakan model spiral. Pada model spiral terdapat iterasi atau revisi berdasarkan masukan dari pengguna (Schwaber, 2004). Tahapan dalam setiap iterasi dalam model spiral meliputi perencanaan (planning), analisis resiko, teknik, dan evaluasi. Poin penting dalam agile adalah interaksi antar anggota tim, karena tanpa adanya interaksi yang baik maka proses pembuatan perangkat lunak tidak akan berjalan sesuai rencana. Fungsi perangkat lunak menjadi lebih penting dari pada dokumentasi. Kolaborasi dengan klien untuk kesesuain keinginan klien. Berfokus pada respon cepat pada perubahan-perubahan saat pembuatan perangkat lunak.

\section{Model Scrum}

Scrum merupakan framework untuk manajemen pengembangan software dengan karakteristik cekatan dan incremental. Scrum menggunakan pendekatan berkala (iterative) dan bertahap (increment) untuk meningkatkan prediktibilitas dan pengendalian resiko(Teams et al., 2013) (Sutherland, 2014) (Lacy, 2013). Gambar 1 menunjukkan tahapan dan pihak yang terlibat dalam scrum. Pendekatan scrum terdiri dari aktifitas, yaitu: 
a) Backlog

Backlog adalah daftar kebutuhan atau fitur yang memberikan nilai bisnis klien, produk backlog yang dibuat dapat bertambah.

b) Sprint

Sprint merupakan unit pekerjaan yang diperlukan untuk memenuhi kebutuhan yang ditetapkan dalam backlog sesuai dengan waktu yang ditetapkan dalam time-box. Selama proses backlog berlangsung tidak ada penambahan.

c) Scrum meeting

Aktifitas scrum meeting merupakan pertemuan rutin yang dilakukan perhari untuk evaluasi apa yang dikerjakan.

d) Demo

Memberikan peningkatan perangkat lunak kepada klien yang telah diimplementasikan dan dapat ditunjukkan serta dievaluasi oleh klien.

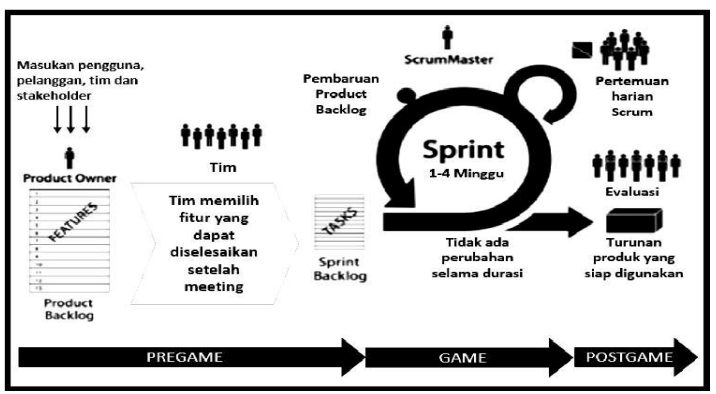

Gambar 1. Tahapan dan pihak yang terlibat

\subsection{Tahapan Penelitian}

Penelitain ini menggunakan metode pengembangan sistem yang mengacu pada metode agile. Gambar 2 menunjukkan tahapantahapan yang dilakukan pada penelitian ini. Tahapan dimulai dari proses perencanaan, analisis resiko, tekinik, dan evaluasi.

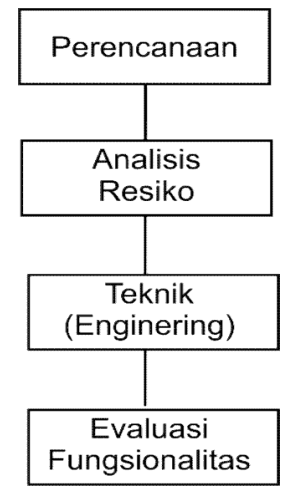

Gambar 2. Tahapan pengembangan sistem Keterangan:

1. Perencanaan

Pada tahap ini, menjelaskan tujuan pengembangan sistem yang akan dibuat. Menjelsakan tentang kendala atau permasalahan selama proses monitoring berlangsung.
2. Analisis resiko

Pada tahapan ini, dilakukan analisis resiko proses bisnis sistem monitoring dan evaluasi clinical pathway di rumah sakit umum isalam harapan anda Kota Tegal.

3. Tekinik

Pada tahapan ini dilakukan pengembangan prototype yang mencakup seluruh kebutuhan sistem sistem monitoring dan evaluasi implementasi clinical pathway. Pada saat sudah sampai pada tahapan teknik peneliti menggunakan model scrum menggunakan pendekatan iterative dan incremental. Tujuanya ialah untuk meningkatkan prediksi serta mengendalikan resiko.

4. Evalusi

Pada tahap ini dilakukan evaluasi dan pengujian funsionalitas sistem, Evaluasi fungsionalitas dilakukan untuk mendapatkan informasi timbal balik dari penguna sistem. Hasil dari kuisioner yang telah diisi oleh responden kemudian diolah untuk mengetahui nilai rata-rata. Persamaan 2.1 bertujuan untuk mendapatkan persentase penilaian.

$$
\bar{X}=\frac{2 x_{1}}{n} \times 100 \%
$$

Keterangan:

$$
\begin{array}{ll}
\bar{x} & =\text { Rata-rata skor } \\
\Sigma x_{i} & =\text { Jumlah skor yang diperoleh } \\
n & =\text { Jumlah skor maksimum }
\end{array}
$$

\section{HASIL DAN PEMBAHASAN}

\subsection{Perencanaan}

1. Tujuan

Penelitian ini bertujuan untuk membantu bagian manajemen perawatan pasien (MPP) di Rumah Sakit Umum Islam Harapan Anda Kota Tegal dalam melakukan proses monitoring kepatuhan setiap profesi terhadap clinical pathway. Dengan adanya sistem monitoring mempersingkat waktu dalam melakukan penilaian, membantu mempermudah dalam proses penyimpanan dan pencarian hasil penilaian implementasi clinical pathway.

2. Pernyataan masalah

Berikut ini adalah pernyataan masalah yang didapat dari hasil wawancara:

a) Pembuatan form penilaian dokter, perawat, gizi, dan farmasi.

b) Pembuatan form penyimpanan dan pencaraian data hasil penilaian.

c) Informasi monitoring rekapitulasi hasil penilaian kepatuhan terhadap implementasi clinical pathway. 
d) Informasi grafik untuk memudahkan dalam membaca laporan rekapitulasi penilaian kepatuhan profesi terhadap clinical pathway.

\subsection{Analisa Resiko}

Tahap selanjutnya melakukan analisis resiko berdasarkan seringnya tigkat kejadian.

Tabel 1. Analisis Resiko

\begin{tabular}{|c|c|c|c|c|c|}
\hline $\begin{array}{l}\mathrm{N} \\
\mathrm{O}\end{array}$ & $\begin{array}{l}\text { Threat and } \\
\text { Vulnerability }\end{array}$ & (P) & (I) & $\mathrm{P}^{*} \mathrm{I}$ & Counter Measure \\
\hline 1 & $\begin{array}{l}\text { Pembuata } \\
\text { n form } \\
\text { penilaian } \\
\text { dokter, } \\
\text { perawat, } \\
\text { gizi, dan } \\
\text { farmasi. }\end{array}$ & 4 & 4 & 16 & $\begin{array}{l}\text { Sistem dapat } \\
\text { memasukkan hasil } \\
\text { tindakan yang tealah } \\
\text { dilakukan oleh setiap } \\
\text { profesi. Sistem dapat } \\
\text { melakukan kuantifikasi } \\
\text { terhadap tindakan- } \\
\text { tindakan yang telah } \\
\text { dilakukan oleh } \\
\text { masing-masing } \\
\text { profesi. }\end{array}$ \\
\hline 2 & $\begin{array}{l}\text { Pembuata } \\
\text { n form } \\
\text { penyimpa } \\
\text { nan dan } \\
\text { pencaraia } \\
\text { n data } \\
\text { hasil } \\
\text { penilaian. }\end{array}$ & 4 & 4 & 16 & $\begin{array}{l}\text { Sistem dapat } \\
\text { melakukan } \\
\text { penyimpanan data } \\
\text { hasil penilaian, sistem } \\
\text { dapat melakukan } \\
\text { pencarian kembali } \\
\text { data hasil penilaian. }\end{array}$ \\
\hline 3 & $\begin{array}{l}\text { Informasi } \\
\text { monitoring } \\
\text { rekapitulas } \\
\text { i hasil } \\
\text { penilaian } \\
\text { kepatuhan } \\
\text { terhadap } \\
\text { implement } \\
\text { asi clinical } \\
\text { pathway. }\end{array}$ & 4 & 4 & 16 & $\begin{array}{l}\text { Sistem dapat } \\
\text { menampilkan seluruh } \\
\text { hasil kepatuhan } \\
\text { maupun ketidak } \\
\text { patuhan terhadap } \\
\text { clinical pathway. } \\
\text { Ketidak patuhan } \\
\text { terhadap clinical } \\
\text { pathway disertai } \\
\text { dengan catatan alasan } \\
\text { yang mendasari } \\
\text { kegitan tersebut tidak } \\
\text { dapat dilakukan } \\
\text { sesuai dengan } \\
\text { aturanya. }\end{array}$ \\
\hline 4 & $\begin{array}{l}\text { Informasi } \\
\text { grafik } \\
\text { untuk } \\
\text { memudah } \\
\text { kan dalam } \\
\text { membaca } \\
\text { laporan } \\
\text { rekapitulas } \\
\text { i penilaian } \\
\text { kepatuhan } \\
\text { profesi } \\
\text { terhadap } \\
\text { clinical } \\
\text { pathway. }\end{array}$ & 4 & 2 & 8 & $\begin{array}{l}\text { Sistem dapat } \\
\text { menampilkan laporan } \\
\text { dalam bentuk grafik } \\
\text { sehingga dapat } \\
\text { membantu MPP } \\
\text { melakukan intepertasi } \\
\text { terhadap data. }\end{array}$ \\
\hline
\end{tabular}

\subsection{Teknik Menggunakan Model Scrum}

Pada tahapan ini, dilakukan penerapanan model scrum dalam pengembangan prototype yang mencakup seluruh kebutuhan sistem monitoring dan evaluasi implementasi clinical pathway di Rumah Sakit Umum Islam Harapan Anda Kota Tegal.

Adapun kebutuhan fungsional dari sistem yang akan dikembangkan: a) Sistem harus dapat mengelola data hasil intervensi yang dilakukan oleh setiap profesi dokkter, perawat, gizi, dan farmasi, dan biodata lengkap pasien.

b) Sistem harus dapat mengelola data prestasi dokter, perawat, gizi, dan farmasi berdasarkan kepatuhannya terhadap clinical pathway.

c) Sistem harus dapat memonitoring rekapitulasi hasil penilaian keaptuahan dokter, perawat, gizi, dan farmasi.

d) Sistem harus dapat digunakan untuk monitoring dengan fitur visual seperti penggunaan grafis histogram, line chart, dan grafik lainnya.

1. Menentukan produk backlog

Langkah pertama scrum adalah penentuan fitur berdasarkan prioritasnya oleh scrum master. Daftar fitur-fitur yang akan dibangun sesuai dengan prioritanya dapat dilihat pada tabel 2 sebagai berikut.

Tabel 2. Produk Backlog

\begin{tabular}{|c|c|c|c|}
\hline No & Deskripsi Fitur & Prioritas & $\begin{array}{l}\text { Estimasi } \\
\text { Waktu } \\
\text { (Jam) }\end{array}$ \\
\hline 1 & $\begin{array}{l}\text { Mengelola data } \\
\text { hasil intervensi } \\
\text { yang dilakukan } \\
\text { oleh setiap } \\
\text { profesi dokkter, } \\
\text { perawat, gizi, } \\
\text { dan farmasi, dan } \\
\text { biodata lengkap } \\
\text { pasien. }\end{array}$ & $\begin{array}{l}\text { Sanat } \\
\text { Tinggi }\end{array}$ & 170 \\
\hline 2 & $\begin{array}{l}\text { Mengelola data } \\
\text { prestasi dokter, } \\
\text { perawat, gizi, } \\
\text { dan farmasi } \\
\text { berdasarkan } \\
\text { kepatuhannya } \\
\text { terhadap clinical } \\
\text { pathway. }\end{array}$ & $\begin{array}{l}\text { Sangat } \\
\text { Tinggi }\end{array}$ & 170 \\
\hline 3 & $\begin{array}{l}\text { Memonitoring } \\
\text { rekapitulasi hasil } \\
\text { penilaian } \\
\text { keaptuahan } \\
\text { dokter, perawat, } \\
\text { gizi, dan farmasi. }\end{array}$ & $\begin{array}{l}\text { Sangat } \\
\text { Tinggi }\end{array}$ & 55 \\
\hline 4 & $\begin{array}{l}\text { Monitoring } \\
\text { dengan fitur } \\
\text { visual seperti } \\
\text { penggunaan } \\
\text { grafis histogram, } \\
\text { line chart, dan } \\
\text { grafik lainnya. }\end{array}$ & $\begin{array}{l}\text { Sangat } \\
\text { Tinggi }\end{array}$ & 55 \\
\hline
\end{tabular}

\section{Menentukan sprint}

Pada tahap ini ditentukan sprint dari produck backlog pada tabel 1. Sprint yang dilakukan berjumlah 4 dengan pertimbangan fitur backlog, task dan estimasi dan sentimasi waktu (jam) sesuai ketentuan dalam scrum. Produk backlog yang akan dikerjakan pada sprint 1 fokus pada kebutuahan aplikasi dari sisi kategori proses pengelolaan data kepatuhan profesi dalam mengimplementasikan clinical pathway. 
Tabel 3. Sprint 1: Proses pengelolaan data setiap profesi dan pasien

\begin{tabular}{|c|c|c|}
\hline Fitur backlog & Task & $\begin{array}{c}\text { Estimasi } \\
\text { waktu }\end{array}$ \\
\hline \multirow[t]{4}{*}{$\begin{array}{l}\text { Pengelolaan } \\
\text { data } \\
\text { kepatuhan } \\
\text { terdap clinical } \\
\text { pathway. }\end{array}$} & $\begin{array}{l}\text { Bagian MPP } \\
\text { menambah data } \\
\text { dokter, pasien, } \\
\text { perawat, gizi, farmasi, } \\
\text { dan data penyakit }\end{array}$ & 56 \\
\hline & $\begin{array}{l}\text { Bagian MPP } \\
\text { memasukkan data } \\
\text { intervensi dokter, } \\
\text { perawat, gizi, dan } \\
\text { farmasi terhadap } \\
\text { pasien }\end{array}$ & 56 \\
\hline & $\begin{array}{l}\text { Bagian MPP } \\
\text { melakukan penilaian } \\
\text { berdasarkan intervensi } \\
\text { dari dokter, perawat, } \\
\text { gizi, dan farmasi }\end{array}$ & 55 \\
\hline & $\begin{array}{l}\text { Bagian MPP dapat } \\
\text { mengubah data hasil } \\
\text { penilaian. }\end{array}$ & 56 \\
\hline
\end{tabular}

Produk backlog yang dikerjakan pada sprint 2 fokus pada kebutuhan aplikasi dari sisi kategori proses pengelolaan data prestasi kepatuhan dokter, perawat, gizi, dan farmasi terhadap clinical pathway. Produk backlog dikerjakan, antara lain:

Tabel 4. Sprint 2: Proses pengelolaan data prestasi profesi

\begin{tabular}{|c|c|c|}
\hline Fitur backlog & Task & $\begin{array}{c}\text { Estimasi } \\
\text { waktu }\end{array}$ \\
\hline $\begin{array}{l}\text { Pengelolaan data } \\
\text { prestasi } \\
\text { kepatuhan dokter, } \\
\text { perawat, gizi, dan } \\
\text { farmasi terhadap } \\
\text { clinical pathway. }\end{array}$ & $\begin{array}{l}\text { Bagian MPP } \\
\text { memasukkan hasil } \\
\text { intervensi dan } \\
\text { melakukan } \\
\text { perhitungan terhadap } \\
\text { intervensi yang sesuai } \\
\text { dengan clinical } \\
\text { pathway dan } \\
\text { intervensi yang tidak } \\
\text { sesuai dengan clinical } \\
\text { pathway }\end{array}$ & 170 \\
\hline
\end{tabular}

Produk backlog yang dikerjakan pada sprint 3 fokus pada kebutuhan aplikasi dari sisi kategori proses monitoring hasil evaluasi terhadap kepatuhan intervensi yang diberikan oleh dokter, perawat, gizi, dan farmasi terhadap clinical pathway.

Tabel 5. Sprint 3: Pengelolaan monitoring rekapitulasi hasil penilaian kepatuhan

\begin{tabular}{llc}
\hline \multicolumn{1}{c}{ Fitur backlog } & \multicolumn{1}{c}{ Task } & $\begin{array}{c}\text { Estimasi } \\
\text { waktu }\end{array}$ \\
\hline $\begin{array}{l}\text { Monitoring } \\
\text { rekapitulasi hasil } \\
\text { penilaian }\end{array}$ & $\begin{array}{l}\text { Bagian dapat } \\
\text { melihat detai hasil } \\
\text { keaptuahan }\end{array}$ & 55 \\
rekapitulasi & penilaian terhadap \\
gizi, dan farmasi & $\begin{array}{l}\text { kepatuhan tindakan } \\
\text { dokter, perawat, gizi, } \\
\text { dan farmasi } \\
\text { terhadap clinical } \\
\text { pathway. }\end{array}$ \\
&
\end{tabular}

Produk backlog yang dikerjakan pada sprint 4 fokus pada kebutuhan aplikasi dari sisi kategori proses monitoring hasil evaluasi dengan menggunakan visualisasi grafik.

Tabel 6. Sprint 4: Pengelolaan monitoring dengan menggunakan grafik

\begin{tabular}{llc}
\hline \multicolumn{1}{c}{ Fitur backlog } & \multicolumn{1}{c}{ Task } & $\begin{array}{c}\text { Estimasi } \\
\text { waktu }\end{array}$ \\
\hline Monitoring & Bagian MPP dapat & 27 \\
menggunakan & melihat & \\
fitur visual seperti & menggunakan & \\
penggunaan & keseluruhan & \\
grafis histogram & tindakan yang & \\
& dilakukan oleh & \\
& setiap profesi. & 27 \\
& Bagian profesi & 27 \\
& dapat melakukan & \\
& komparasi & \\
& terhadap setiap & \\
& kepatuhan dokter & \\
& secara individu & \\
& dengan dokter \\
& individu yang \\
& lainnya. \\
\hline
\end{tabular}

\subsection{Demo}

Aktifitas selanjutnya yang dilakukan sesuai model scrum adalah demo, tujuanya memberikan peningkatan peningkatan fungsi perangkat lunak kepada klien. Perangkat lunak sudah dapat ditunjukkan dan dievaluasi oleh klien. Hasil dari tahap teknik adalah sebuah perangkat lunak sistem monitoring terhadap implementasi clinical pathway.

Gambar 3 form isi data menunjukkan adanya fungsi data yang terkait dengan biodata dokter seperti NIK, nama dokter, dan nama dokter spesialis.

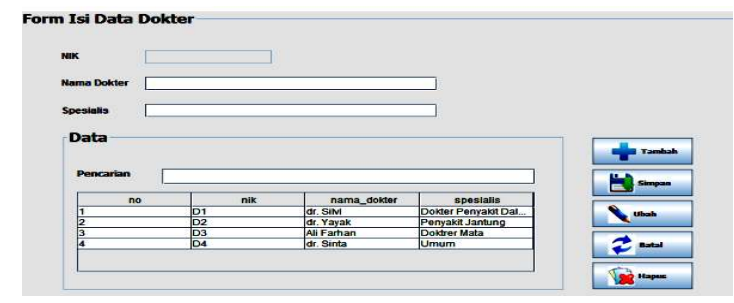

Gambar 3. Form input data dokter

Gambar 4 menunjukkan form isi data penyakit yang berfungsi untuk memasukkan data-data yang terkait dengan penyakit yang telah dibuatkan clinical pathway nya.

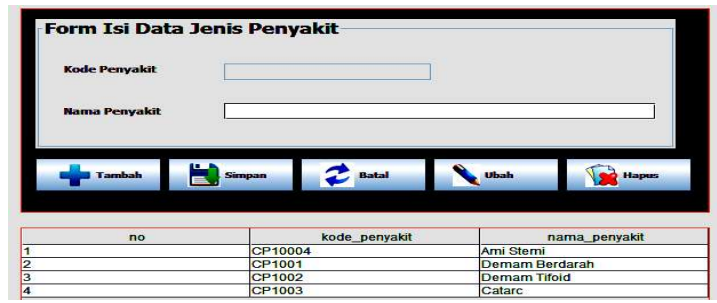

Gambar 4. Form Input Data Penyakit 
Gambar 5 merupakan grafik form histogram berfungsi untuk mempermudah dalam mengetahui kepatuhan setiap profesi terhadap clinical pathway masing-masing jenis penyakit.

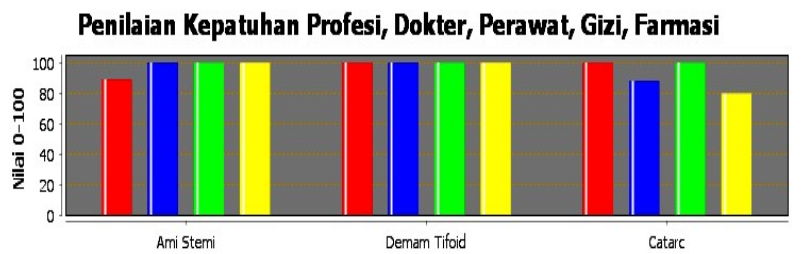

Gambar 5 Grafik histogram kepatuhan profesi

Gambar 6 merupakan grafik form histogram bertujuan untuk mengetahui kepatuhan setiap dokter terhadap clinical pathway.

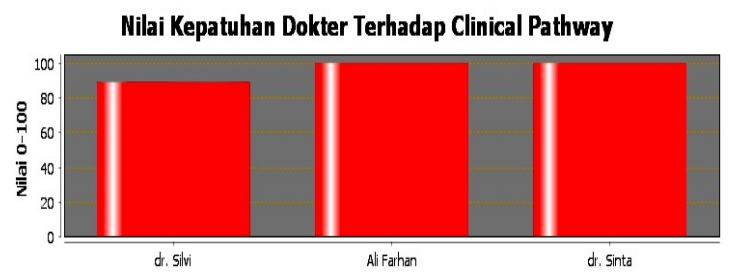

Gambar 6 Kepatuhan individu dokter pada clinical pathway

\subsection{Evaluasi Fungsionalitas Sistem}

Evaluasi fungsionalitas dilakukan untuk mendapatkan informasi timbal balik dari penguna sistem. Hasil dari kuisioner yang telah diisi oleh responden kemudian diolah untuk mengetahui nilai rata-rata.

Pengguna sistem ini adalah staf bagian manajemen perawatan pasien (MPP) di Rumah Sakit Islam Harapan Anda. Staf MPP memiliki tiga karywan yang bertugas melakukan input data maupun penilian terhadap dokumen clinical pathway. Indikator penilaian sistem dibagi menjadi tiga penilaian kualitas sistem, kualitas informasi, dan kualitas layanan. Deskripsi penilian memiliki skala satu hingga empat, dimana peniliaian sangat tidak setuju (STS) sama dikuantifikasi dengan bobot 1, Tidak Setuju (TS) dikuantifikasi dengan bobot 2 , Setuju (S) dikuantifikasi dengan bobot 3, dan Sangat Setuju (SS) dikuantifikasi dengan bobot sebanyak 4 poin.

Kuisioner yang telah dibagikan kepada pengguna tampak seperti pada lampiran fungsionalitas sistem sistem dibagi menjadi tiga kategori yaitu penilaian terhadap kualitas sistem, kualitas informasi, dan kualitas layanan. Kualitas sistem ini berkaitan dengan karakteristik yang berhubungan dengan antarmuka (interface) seperti kemudahan penggunaan, waktu respon, dan bahasa. Berdasarkan skala nilai intepertasi skor fungsionalitas pada Tabel 7 fungsionalitas sistem.
Tabel 7. Interpretasi skor fungsionalias sistem

\begin{tabular}{cl}
\hline Presentase & \multicolumn{1}{c}{ Kriteria } \\
\hline $0 \%-25 \%$ & Sangat tidak sesuai \\
$26 \%-50 \%$ & Tidak sesuai \\
$51 \%-75 \%$ & Cukup sesuai \\
$76 \%-100 \%$ & Sesuai \\
\hline
\end{tabular}

Kualitas sistem monitoring dan evaluasi clinical pathway dinyatakan sesuai dengan fungsinya karena memperoleh nilai sebanyak $76 \%$. Penilaian terhadap kualitas informasi, penilaian meliputi keakuratan informasi, kelengkapan informasi. Penilaian kualitas informasi cukup sesuai dengan fungsinya, karena memperoleh presentase nilai sebanyak $68 \%$. Kualitas layanan sistem monitoring dang evaluasi clinical pathway juga cukup sesuai dengan fungsinya dengan perolehan nilai sebanyak $63 \%$, pada penilaian kualitas sistem menjelaskan tentang produktivitas pengguna, kemudahan, serta efektivitas sistem dalam membantu menyelesaikan pekerjaan bagi penguna sistem.

\section{KESIMPULAN}

Penerapan clical pathway tidak dapat direalisasikan secara sempurna hal ini disebabkan berbagai hal misalnya, kekurangan sumber daya peralatan, fasilitas kesehatan atau dapat terjadi karena kelalaian dari pelaksana teknis dokter, perawat, gizi, dan farmasi. Sistem monitoring clinical pathway menjadi penting untuk dapat mengetahui hambatan yang muncul. Untuk mendukung proses monitoring dan evaluasi agar lebih cepat. Pada penelitian ini dibangun sistem dengan menggunakan metode agile dengan model scrum.

Hasil fungsionalitas terbagi menjadi tiga, pertama hasil kualitas sistem sebanyak $76 \%$ sesuai dengan fungsi. Kedua penilaian terhadap kualitas infomasi yang dihasilkan oleh sistem yaitu sebanyak $68 \%$ sesuai dengan fungsinya. Ketiga penilaian terhadap kualitas layanan sebanyak $63 \%$ sesuai dengan fungsinya.

\section{REFERENSI}

Djasri, H. (2016). Peran Clinical Pathways dalam Sistem Jaminan Sosial Nasional Bidang Kesehatan. PDPERSI.

Huang, Z., Dong, W., Ji, L., \& Duan, H. (2016). Predictive Monitoring of Clinical Pathway. Expert System, 227-241.

Kopec, D., Shagas, G., Reinharth, D., \& Tamang, S. (2004). Development of a Clinical Pathways Analysis System with Adaptive Bayesian Nets and Data Mining Techniques. Health Technology and Informatics, 1-112. 
Lacy, M. (2013). The Scrum Field Guide Practical Advice for Your First Year. Addison Wesley.

Rahma, P. A. (2013). Implementasi Clinical Pathway Untuk Kendali Mutu dan Kendali Biaya Pelayanan Kesehatan.

Schwaber, K. (2004). Agile Project Management with Scrum (Issue $\mathrm{Cmm}$ ). Microsoft Press.

Sjaf, A. C., Junadi, P., \& Nurwahyuni, A. (2015). Tools Pengembangan Clinical Pathway dan Evaluasi Clinical Pathway Konsep dan Penggunaanya. UI.

Sulistiyo, H. R., Darmadjaja, D., Lalopua, E., Lumenta, N., Haryati, T. S., Soeroso, S., \& Abinin, Z. (2015). CLINICAL PATHWAY

\section{DALAM ASUHAN TERINTEGRASI SESUAI STANDAR AKREDITASI RUMAH SAKIT 2012. Kemenkes.}

Sutherland, J. (2014). Scrum The Art of Doing Twice The Work in Half The Time. Crown.

Sutisna, N. S. (2017). Pentingnya Clinical Pathway Bagi Fasilitas Kesehatan.

Teams, C. A., Scrum, E., \& Scrum, E. (2013). Praise for Essential Scrum. Addison Wesley.

Vanhaet, K. (2007). The Impac of Clinical Pathways on The Organisations of Care Process. ACOO Leuven.

Wally, B., Boy, B., \& Joko, L. (2013). Analisis Perancangan Aplikasi Clinical Patway Pada Rumah Sakit PHC Surabaya. 